\title{
Investigation on the Effects of Heat Sink on the Performance of Thermoelectric Generator for Human Body Heat Harvesting
}

\author{
Tan Kuan You ${ }^{1}$, Hassan Mohamed ${ }^{2}$, Madihah Mujaini ${ }^{3}$ \\ ${ }^{1}$ College of Engineering, Universiti Tenaga Nasional, Malaysia, kytan0127@ gmail.com \\ ${ }^{2}$ Institute of Sustainable Energy, Universiti Tenaga Nasional, Malaysia,mhassan@uniten.edu.my \\ ${ }^{3}$ College of Engineering, Universiti Tenaga Nasional, Malaysia, madihah@ uniten.edu.my
}

\begin{abstract}
In recent years, thermoelectric power generation from waste heat has been considered as a promising alternative green and clean energy. In this study, the effects of different heat sink types (flat and checkerboard pattern) on the power output of thermoelectric generator (TEG) in harvesting human body heat are investigated. Several sets of experiments are conducted on three different body part locations, namely forehead, forearm, and wrist of different individuals of different genders by considering parameters such as surrounding temperature, skin temperature, output voltage and current. The values of power generated from the TEG are calculated and analysed. The findings show that the addition of copper heat sink to the basic TEG had generally increased the average power output across the board for all body parts and modes of activities. While the addition of heat sinks on the TEG increases the power output.Additionally, the checkerboard heat sinks have larger impact to the performance of TEG with an additional power incremental of $23.8 \%$ as compared to flat heat sinks (183.8\% incremental) due to the larger surface area for faster heat dissipation.
\end{abstract}

Key words: Energy harvester, heat sink, thermoelectric generator (TEG), waste heat.

\section{INTRODUCTION}

In the applications of mobile electronics and portable devices, the traditional electrochemical batteries are commonly used as the power source. However, batteries have limited power storage and need to be charged or replaced after some time[1]. In this case, thermoelectric generator (TEG) devices have the potential to produce a sustainable and continuous power [2]. Human body releases approximately 100 to525W of heat which can be converted into electrical energy [3], depending on the locations of the TEG placement [4]. According to the Seebeck effect, the power produced by the TEG is proportional to the temperature difference between the two sides of device; hot surface that is in contact with the skin and the cold surface exposed to the environment [5]. The use of thermoelectric generators in harvesting body heat is possible based on previous studies by Rosli and Mohamed[6]. The experiment was conducted on two human samples under different human activities on different location of the body and showed that a specific body part generates the maximum power. However, the energy converted is not large and efficient. The temperature gradient between two surfaces decreases as the surface exposed to the surrounding gets warmer after a certain duration due to the operation and thermal resistance of the device.

Heat sink is a device that acts like heat exchanger to enhance heat dissipation from the hot surface to the ambient air to regulate the temperature of component at optimum level. Different types of heat sinks can be used in thermoelectric generator to dissipate heat. Currently, heat sink for thermoelectric generators can be classified into two categories which are passive (passive cooling, semi-active cooling) and active (active cooling, liquid cooling and phase change cooling)with their parameters shown in Table 1 [7]. In the application of heat sink on low power density TEG for harvesting human body heat, passive cooling heat sink is more suitable to be used as they do not have moving parts and can be in small size. Passive heat sinks are most reliable and only require natural air convection to dissipate heat [7]. This type of heat sink can simply be a heat spreader flat plate, plate with pattern or structure with various fin designs. Improving the heat dissipation may increase the conversion efficiency. Hence, future practical TEG applications such as small smart energy harvesting and e-health monitoring devices can be made possible[8].

\section{METHODOLOGY}

The detailed process flow of the experiment is illustrated in Error! Reference source not found.

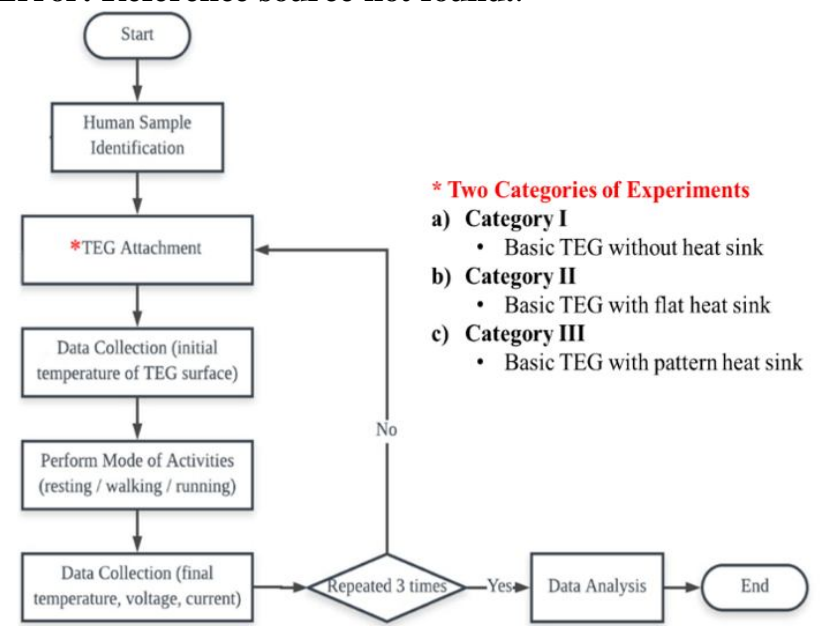

Figure 1: Process flow chart for TEG experiment 
Tan Kuan You et al., International Journal of Emerging Trends in Engineering Research, 8(5), May 2020, 1902 - 1905

Table1: Heat sink classification [6]

\begin{tabular}{|l|l|l|l|l|}
\hline \multicolumn{1}{|c|}{$\begin{array}{l}\text { Heat sink } \\
\text { category }\end{array}$} & \multicolumn{1}{|c|}{ Advantages } & \multicolumn{1}{c|}{ Disadvantages } & \multicolumn{1}{c|}{ Examples } \\
\hline Passive & $\begin{array}{l}\text { User friendly } \\
\text { Readily available } \\
\text { Cheap }\end{array}$ & $\begin{array}{l}\text { Power dissipation } \\
\text { capacity is limited }\end{array}$ & $\begin{array}{l}\text { Natural } \\
\text { convection/systems } \\
\text { Not dependent on air } \\
\text { flow } \\
\text { Simple power } \\
\text { intensity uses }\end{array}$ & Metal plate \\
\hline Semi-active & $\begin{array}{l}\text { In relation to first one it has } \\
\text { low thermal resistance for the } \\
\text { same area }\end{array}$ & $\begin{array}{l}\text { Limited in } \\
\text { capability of power } \\
\text { dissipation }\end{array}$ & $\begin{array}{l}\text { Medium power } \\
\text { intensity uses }\end{array}$ & Fin heat sink \\
\hline Active & $\begin{array}{l}\text { Combine fan and heat sink } \\
\text { into one unit } \\
\text { Produce much heat } \\
\text { dissipation capacity in } \\
\text { relation to previous types }\end{array}$ & $\begin{array}{l}\text { Long term } \\
\text { reliability }\end{array}$ & $\begin{array}{l}\text { High power intensity } \\
\text { uses }\end{array}$ & $\begin{array}{l}\text { Fan-fins heat } \\
\text { sink }\end{array}$ \\
\hline $\begin{array}{l}\text { Liquid } \\
\text { cooling }\end{array}$ & $\begin{array}{l}\text { Produce much heat } \\
\text { dissipation capacity more } \\
\text { than all previous types }\end{array}$ & $\begin{array}{l}\text { Complicated } \\
\text { Expensive }\end{array}$ & $\begin{array}{l}\text { High power intensity } \\
\text { uses }\end{array}$ & $\begin{array}{l}\text { Liquid cold } \\
\text { plate }\end{array}$ \\
\hline $\begin{array}{l}\text { Phase } \\
\text { change } \\
\text { cooling }\end{array}$ & $\begin{array}{l}\text { Heat is distributed evenly } \\
\text { fast }\end{array}$ & $\begin{array}{l}\text { Complicated } \\
\text { Expensive } \\
\text { Need extra area }\end{array}$ & $\begin{array}{l}\text { High power intensity } \\
\text { uses }\end{array}$ & $\begin{array}{l}\text { Vapor } \\
\text { compression } \\
\text { phase change } \\
\text { cooler }\end{array}$ \\
\hline
\end{tabular}

the temperature of both surfaces (hot and cold side). For the

In order to identify the optimum location of human body for heat harvesting and the means to maximize the power generated by such a system, various tests were performed in a controlled laboratory setting (gym enclosure with constant ambient air temperature of $28^{\circ} \mathrm{C}$ at minimal air flow for natural convection) to characterize the response of TEG with and without tightening effect. All the experiments involved the preparation of TEG devices, measuring equipment and the copper plates of specific dimensions and patterns as the heat sink material. Copper heat sink was selected because of its relative advantages over other materials in terms of thermal conductivity, availability and affordability.

Several tests were conducted with basic TEG on three different body part locations, which are forehead, forearm, and wrist. These specific locations are chosen for the study because most likely people can readily expose these areas to the ambient without causing much hindrance or discomfort while performing their other activities at the same time. Each test using basic TEGwas performed on three different modes of human activities, namely resting, walking and running. After completing all these tests, the similar experiments were repeated with basic TEG again but this time in maximizing its power generation, similar sets of tests were carried out with the flat and checkerboard copper heat sinks attached onto the TEG.

\subsection{Optimizing the Lighting System}

The thermoelectric generator (TEG) module was inserted into a 3D printed casing as shown inError! Reference source not found.. With some adjustments, the Velcro straps were then installed onto the casing slots. Type-K thermocouples were attached properly to the top and bottom of the TEG to obtain experiment with heat

sink, the copper heat sink was installed on top of the TEG cold surface that was exposed to the surrounding.

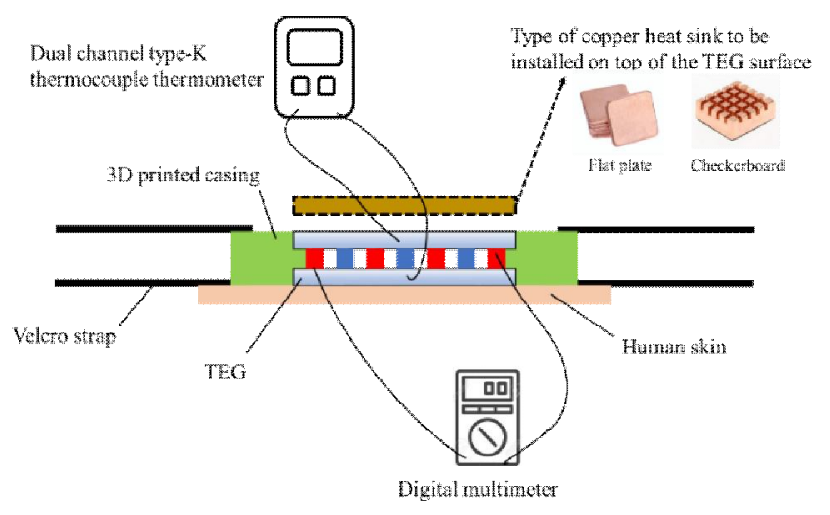

Figure 2: Illustration of basic TEG device assembly

The simple circuit was constructed as shown in Error! Reference source not found.to obtain the output voltage and current readings at the load resistor. 


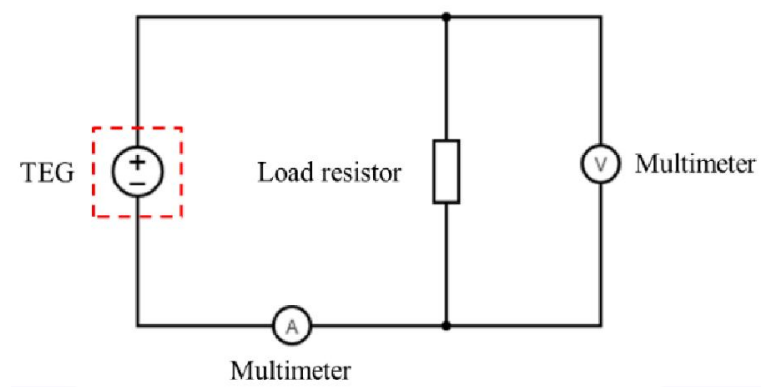

Figure 3: Circuit diagram for voltage and current measurement

The total number of individual set for the experiment was 6 , which consists of 3 males and 3 females. The participants were selected under the age group of 18 to 25 years old. The height, weight and body mass index of every individual were measured. The preassembled TEG device was placed on the targeted part of human skin. It was wrapped and secured nicely by the Velcro straps, firmly around the body part location.

There were three different types of activities, namely resting, walking and running, to be performed separately in each test. The individual started with resting mode measurement by simply sitting on a chair. As in walking and running modes, the individual walked on a treadmill with the speed being set to $20 \mathrm{~min} / \mathrm{km}(0.833 \mathrm{~m} / \mathrm{s}$ or $3 \mathrm{~km} / \mathrm{hr})$ and $10 \mathrm{~min} / \mathrm{km}(1.667 \mathrm{~m} / \mathrm{s}$ or $6 \mathrm{~km} / \mathrm{hr}$ ), respectively. Each activity was carried out for 10 minutes and the data were recorded. Each activity was repeated for 3 times to obtain an average reading. Subsequently, the next mode of activity was performed. It is important to note that after each test, the device was unwrapped and detached for five minutes break interval in order to allow the skin temperature and the TEG to cool down to a normal ambient temperature.

The process of data collection happened before and after the activities were performed. The temperatures on both sides of

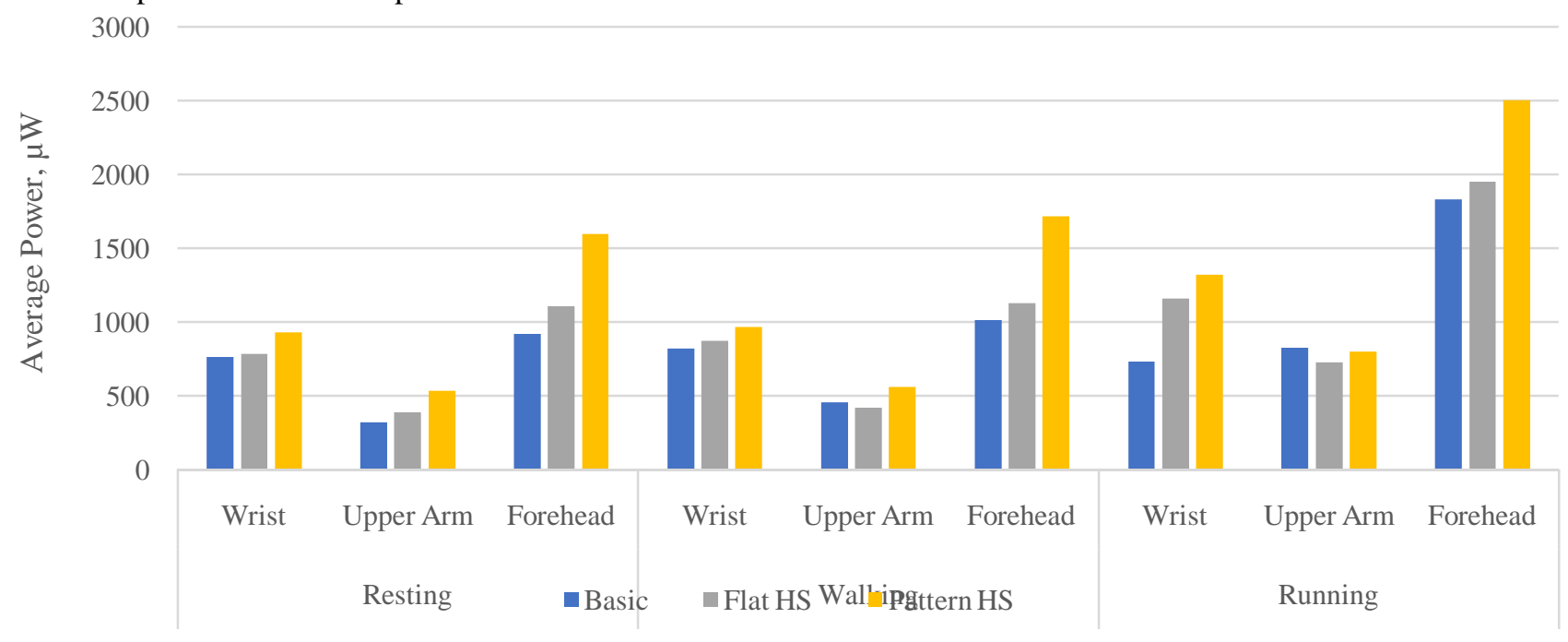

Figure 4: Effect of heat sink on basic TEG (male). the device, which are the surface attached to the skin and surface exposed to the surrounding, were measured and recorded by the thermocouple thermometer before and after every activity to determine the temperature difference. The digital multimeter was used to measure the voltage and the current produced by the TEG after each activity. The data were then tabulated and analyzed.

The experiment was repeated with the additional step of attaching the copper heat sink to the cold surface of the TEG before performing each activity. The power output, $P$ can be calculated using the voltage $V$ and current $I$ as per the following formula,

$$
P=V I .
$$

\section{RESULTS AND DISCUSSION}

The raw data were tabulated and generated into graphs. Error! Reference source not found.and Error! Reference source not found.showed the effects of types of copper heat sink, which are flat and checkerboard, on the power generated from basic TEG for male and female samples, respectively.Referring to Error! Reference source not found.andError! Reference source not found., the addition of copper heat sink to the basic TEG had generally increased the average power output across the board for all body parts and modes of activities. The heat sink helped to increase the rate of heat dissipation from the top surface of the TEG, which further increased the temperature difference across the module and resulted in higher power generation. 
Tan Kuan You et al., International Journal of Emerging Trends in Engineering Research, 8(5), May 2020, 1902 - 1905

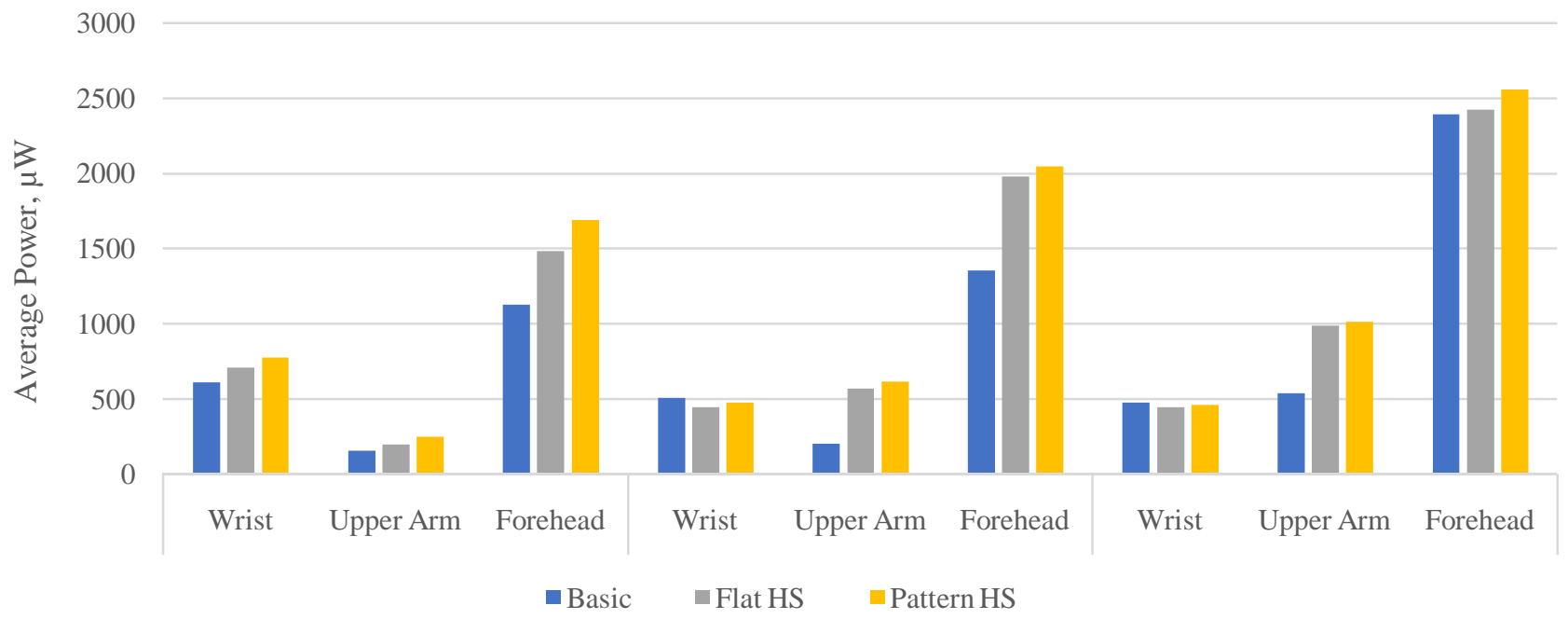

Figure 5: Effect of heat sink on basic TEG (female).

For male category, the largest increment in power output occurred at the wrist during running mode. With the addition of flat heat sinks, the power output was $58.4 \%$ higher than basic TEG, while checkerboard heat sinks further increased an additional of $22.1 \%$ from flat heat sink. For female category, the largest increment in power output occurred at the upper arm during walking mode. The power output increased by $183.8 \%$ with the attachment of flat heat sink, and further increased an additional of $23.8 \%$ with checkerboard heat sink.

\section{CONCLUSION}

This investigation is helpful in determining the effects of different types of heat sink to the power output of TEG from harvesting human body heat. The addition of copper heat sink to the basic TEG has generally increased the average power output across the board for all body parts and modes of activities. While the addition of heat sinks on the TEG increases the power output, the checkerboard heat sinks have larger impact to the performance of TEG with an additional power incremental of $23.8 \%$ as compared to flat heat sinks (183.8\% incremental) due to the larger surface area for faster heat dissipation.

\section{ACKNOWLEDGMENT}

The authors would like to express sincere appreciation to UNITEN for providing financial assistance to conduct this work under the BOLD 2025 PHASE 2 Research grant (10436494/B/2019073).

\section{REFERENCES}

[1] D. P. Arnold, "Review of microscale magnetic power generation," IEEE Trans. Magn., vol. 43, no. 11, pp. 3940-3951, Nov. 2007, doi: 10.1109/TMAG.2007.906150.

[2] M. Hyland, H. Hunter, J. Liu, E. Veety, and D. Vashaee, "Wearable thermoelectric generators for human body heat harvesting," Appl. Energy, vol. 182, pp. 518-524, Nov. 2016, doi: 10.1016/J.APENERGY.2016.08.150.

[3] A. R. M. Siddique, S. Mahmud, and B. Van Heyst, "A review of the state of the science on wearable thermoelectric power generators (TEGs) and their existing challenges," Renew. Sustain. Energy Rev., vol. 73, pp. 730-744, Jun. 2017, doi: 10.1016/J.RSER.2017.01.177.

[4] K. Shin, "On the Selection of Sensor Locations for the Fictitious FRF based Fault Detection Method," Int. J. Emerg. Trends Eng. Res., vol. 7, pp. 569-575, Nov. 2019, doi: 10.30534/ijeter/2019/277112019.

[5] Z. Lu, H. Zhang, C. Mao, and C. M. Li, "Silk fabric-based wearable thermoelectric generator for energy harvesting from the human body," Appl. Energy, vol. 164, pp. 57-63, Feb. 2016, doi: 10.1016/J.APENERGY.2015.11.038.

[6] N. Rosli and H. Mohamed, "Experimental Study on the Use of Thermoelectric Generators in Harvesting Human Body Heat," Int. J. Eng. Technol., vol. 7, pp. 264-269, Nov. 2018, doi: 10.14419/ijet.v7i4.35.22744.

[7] A. Elghool, F. Basrawi, T. K. Ibrahim, K. Habib, H. Ibrahim, and D. M. N. D. Idris, "A review on heat sink for thermo-electric power generation: Classifications and parameters affecting performance," Energy Convers. Manag., vol. 134, pp. 260-277, Feb. 2017, doi: 10.1016/J.ENCONMAN.2016.12.046.

[8] S. K, "E-Health based Patient Surveilling Device," Int. J. Emerg. Trends Eng. Res., vol. 8, pp. 792-796, Mar. 2020, doi: 10.30534/ijeter/2020/30832020. 